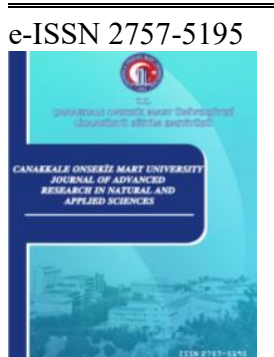

Çanakkale Onsekiz Mart University

Journal of Advanced Research in Natural and Applied Sciences

Open Access

doi.org/10.28979/jarnas.845193

2020, Vol. 6, Issue 2, Pages: 303-316

dergipark.org.tr/tr/pub/jarnas

\title{
A Wet-Stock Management and Leak Detection System for Fuel Tanks
}

\author{
Ayşe Nur Dalman ${ }^{1}$, M. Oluş Özbek ${ }^{2, *}$ \\ ${ }^{1}$ Department of Chemical Engineering, Graduate School of Natural and Applied Sciences, Yeditepe University, Istanbul, Turkey \\ ${ }^{2}$ Department of Chemical Engineering, Faculty of Engineering, Gebze Technical University, Kocaeli, Turkey
}

$\begin{array}{lr}\text { Article History } \\ \text { Received: } & 12.02 .2020 \\ \text { Accepted: } & 18.10 .2020 \\ \text { Published: } & 29.12 .2020\end{array}$

Research Article

\begin{abstract}
One of the critical problems in wet-stock management is inaccurate (poor) tank calibration that masks the leakages from the underground storage tanks (USTs). Moreover, obtaining the correct tank parameters or recalibration is an expensive procedure if not impossible. This study aims to prevent the masking effect of several tank parameters on the tank calibration chart and to improve the leak detection and wet-stock management for fuel storage tanks. This goal is achieved through obtaining the mathematical models for simple cylindrical tank that convert the measured liquid height to accurate liquid volume by taking into account the tank deformations. The accounted deformations in tank parameters are errors in radius, length, probe offset and axial and radial tank tilts, as well as volume change with temperature. The simulations using the actual data gathered from a commercial fuel service station showed that the approach developed in this study is valid. The deformation included tank models successfully predicted the real fuel volumes. The results showed that the variance reduced from $-300 \mathrm{~L}-+100 \mathrm{~L}$ range to $-20 \mathrm{~L}-$ $+20 \mathrm{~L}$ range for, which brings $67.2 \%$ improvement over the cumulative variance. This study also shows that obtaining the precise volume measurements by introducing models that account for the deformations in the UST is possible.
\end{abstract}

Keywords - Fuel station, fuel tank calibration, wet-stock management, UST, leak detection

\section{Introduction}

Fuel service stations store commercial grades of fuels in underground storage tanks (USTs) that should be prevented from leakage (ERC, 2016). Thus, station owners and operators have responsibilities for the safe management of these hazardous chemicals (Queensland, 2016).

An UST system consists of a storage tank and its piping, and should comply with the regulations (EPA, 2015, 2017; ERC, 2016; TORA, 2016). Otherwise releases from UST systems in the form of spill, overfill, leak through tank wall or associated piping can contaminate underground water (EPA, 2013) and/or can cause fires or explosions (AFC, 2010). In 2000, this kind of an explosion caused deaths of two people and injuries of three people in a fuel service station in Istanbul (TORA, 2016).

Leak detection is crucial for environmental safety, sustainability and economical running of the station (Shinn, 2001). It necessitates periodic monitoring of the tank and its piping (EPA, 2017). Several leak detection methods are commercially available, such as secondary containment with interstitial monitoring (EPA, 2005, 2015), automatic tank gauging (ATG) (EPA, 2005, 2015), vapour monitoring (including tracer compound analysis) (EPA, 2005, 2015), statistical inventory reconciliation (SIR) (EPA, 1995; Keating \& Mason, 2000) and groundwater monitoring (EPA, 2005, 2015). Most of these leak detection methods require specialized equipment and techniques (Gorawski, Gorawska, \& Pasterak, 2017). On the other hand, algorithmic solutions that

\footnotetext{
1 (D) dalmanaysenur@gmail.com

2 (D) olus.ozbek@gtu.edu.tr

${ }^{*}$ Corresponding Author
} 
does not require specialized equipment are also possible (Gorawski et al., 2017). The leak threshold for tank and pipe varies by techniques, whose number exceeds 390 (NWGLDE, 2020). Approval or acceptance of release detection systems rests within implementing agency, which in most cases is the state's environmental agency. In general, the leak threshold is given as $0.4 \mathrm{~L} / \mathrm{h}$ for tanks (NWGLDE, 2020). In Turkey, "EN 131605 Leak detection systems - Part 5" (EN, 2016) norms and "TS 12820 Petrol filling stations - Safety requirements" (TSE, 2006) are accepted and fulfilled/implemented. In accordance these, the leak detection capability must be at least and below $0.4 \mathrm{~L} / \mathrm{h}$.

In 2006, Turkey began to deal with leak detection by announcing "TS 12820 Petrol filling stations - Safety requirements" (TSE, 2006) that covers safety requirements for petrol filling stations. However, enough data for statistical purposes has not been gathered since. Nonetheless, leak detection methods for fuel tanks have been discussed in the newest draft of this standard in 2016. The latest update on this subject by EMRA states that the inventory management and leak detection should be carried out on tank bases, rather than product bases (EPDK, 2019).

It is clear that leak detection goes hand in hand with the inventory control and wet-stock management (WSM) (EPA, 2013; Yorkshire, 2014). Since USTs are transient systems without any generation or consumption the mass balance reduces to Eq.1.1 under constant density assumption.

$$
\frac{d V_{\text {fuel }}}{d t}=\dot{V}_{\text {delivery }}-\dot{V}_{\text {sales }}
$$

In Eq. 1.1, $\mathrm{V}_{\text {fuel }}$ denotes the volume of the fuel in the tank, $\dot{\mathrm{V}}_{\text {delivery }}$ denotes the volumetric rate of delivery, and $\dot{V}_{\text {sales }}$ denotes that of dispensed volume from tank. In WSM, the problem arises when the Eq. 1.1 is not satisfied. Then, the missing (loss) or extra (gain) is attributed to the variance (Var) term (Eq. 1.2), which is the difference between the calculated amount of fuel in the tank, and the actual amount of fuel in the tank.

$$
\text { Var }=V_{\text {final }}-\left(V_{\text {initial }}+V_{\text {delivery }}-V_{\text {sales }}\right)
$$

For a better understanding, variance should be investigated under two headings, i) real variance, and, ii) apparent variance. The real variance shows the real losses (VR, 2016) caused by volume change because of temperature, evaporation, leaks, etc. On the other hand, wrong tank calibration or measurement errors cause an artificial volume difference, which is attributed to the apparent variance (APEA, 2009; VR, 2013, 2015, 2016).

Errors in liquid height to liquid volume conversions are a major cause for apparent fuel variance. Furthermore, the mismatch in the fuel volume measurements is an important factor that hides the leaks and/or causes false alarms. The fuel volume is estimated by measuring the liquid height using a probe (VR, 2009, 2015). The level signal is then processed by the tank level sensor (TLS) unit, which converts the height signal to liquid volume according to tank calibration chart. The main causes for the wrong conversions are i) inaccurately reported tank dimensions, ii) tank deformations, iii) tank or the probe inclinations.

It should be noted that measurement of tank dimensions, which is already underground, is not feasible nor possible (Caihong Li, 2013). Since common calibration techniques (ASIS, 2017; Jin Tao Wang, 2013; Khaisongkram \& Banjerdpongchai, 2004; Knyva \& Knyva, 2012; Mensura, 2013) are not preferable, recalibration is generally carried out using some sort of an estimation technique that uses a mathematical model (Caihong Li, 2013; Chen, 2012; Y. Li, 2014; Nosach, 2000; Xie, Wang, Cui, \& Chen, 2012). These techniques parameterize the tank geometry (Caihong Li, 2013; Y. Li, 2014; Nosach, 2000; Xie et al., 2012), probe position (Nosach, 2000), and inclination of the tank (Caihong Li, 2013; Chen, 2012; Y. Li, 2014; Nosach, 2000; Xie et al., 2012) to differentiate between the ideal volume and the calibrated volume of the underground storage tanks. Most of these works focus only on the axial and/or radial tilts of the tanks and correcting the height to 
volume charts without considering the fuel variance and/or the leak detection. On the other hand, a few of the studies focus on the wet-stock management and variance (leak) control, without considering the corrections for the tank calibrations. However, a study that takes in account all the deformation parameters that cause the variance term, nor a study that combines the parameter based volume correction and the variance control is not available in the open literature.

Thus, this study builds a geometrical model based algorithm that can be used for wet-stock management and leak detection for the fuel stations that use USTs. The core of the study is the model based approach that takes in account all the tank deformation parameters (axial tilt, radial tilt, temperature effect) and corrects the calibration charts without the necessity of specialized equipment. By estimating the correct fuel volumes tracking the variance, and therefore the leaks, become possible.

\section{Methodology}

We considered a fuel storage tank whose shape is simple cylinder without dished heads. Under ideal conditions, as Figure 1.a shows, the simple cylinder tank (SCT) lies perfectly horizontal on the ground and the probe is placed perpendicular in the central axis. At this point, the liquid volume can be expressed as a function of tank radius (R), tank length (L) and instant fuel height (h) as follows.

$$
V(h)=L\left[\sqrt{2 R h-h^{2}}(h-R)+R^{2} \cos ^{-1}\left(1-\frac{h}{R}\right)\right]
$$

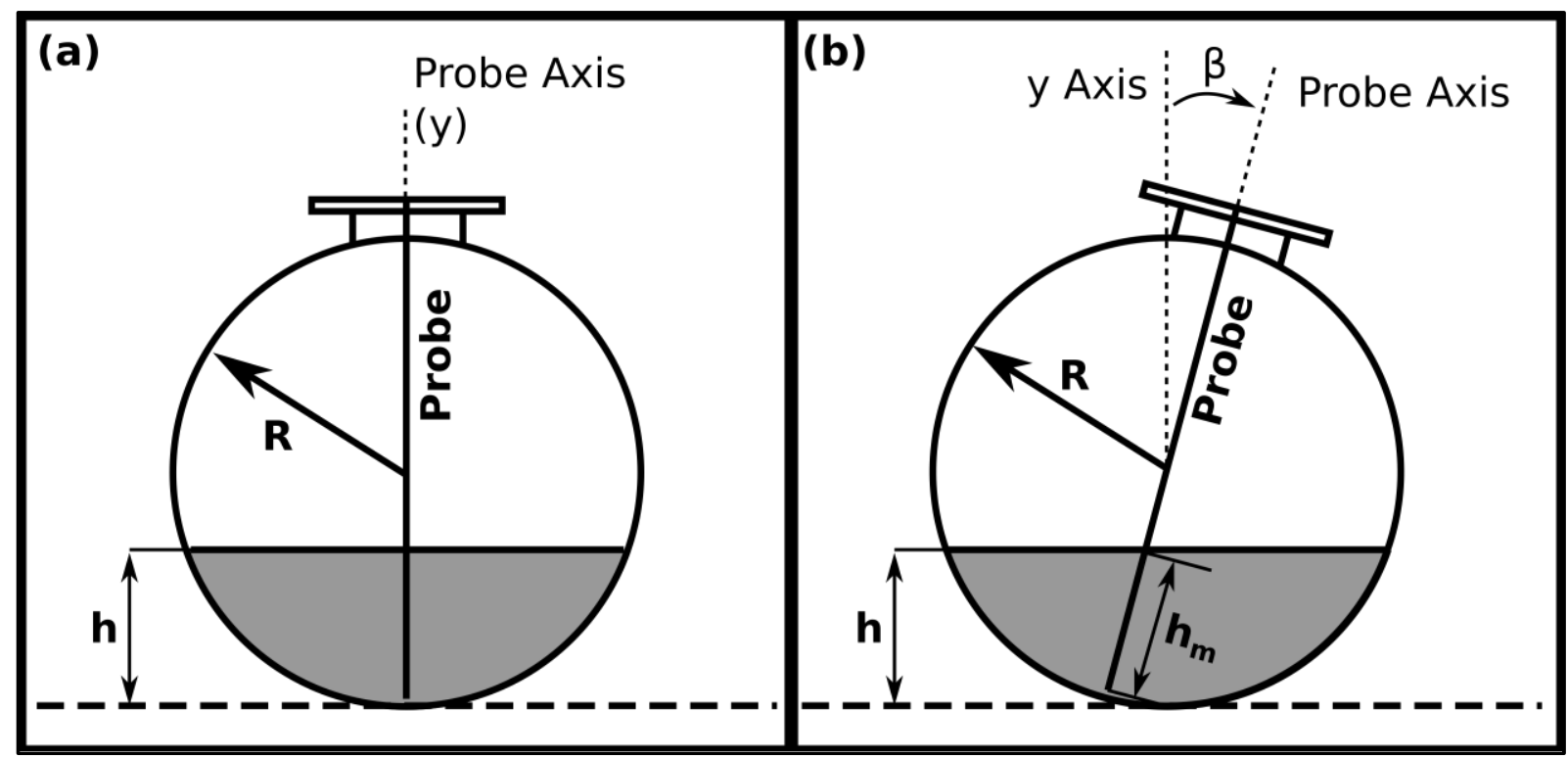

Figure 1. The side view of SCT (a) without and (b) with radial tilt. The parameters are: R: Tank radius, h: Instant fuel height, $\mathrm{h}_{\mathrm{m}}$ : Measured fuel height, $\beta$ : Radial tilt angle.

Under non-ideal conditions, the tank can be tilted axially (i.e. $\alpha$ ), radially (i.e. $\beta$ ), or both. Using trigonometric relations to calculate the wet probe height and following a similar procedure as in (Caihong Li, 2013; Xie et al., 2012) corrected relations can be obtained. When the tank or the probe tilt along the radial axis with $\beta$ degrees (Figure 1.b), the correct fuel volume can be calculated by correcting the measured height $\left(h_{m}\right)$.

$$
h=\frac{h_{m}}{\sec \beta}+2 R \sin ^{2} \beta
$$

In the case of a tilt in tank's axial direction $(\alpha)$, non-measurable liquid volumes, when the fuel level lye below the probe (Figure 2.a and Figure 2.b), should be taken into account as well. Here again, using the trigonometric 
relations and a similar procedure as in in (Caihong Li, 2013; Xie et al., 2012) it is possible to find the correct level. Depending on the tilt direction non-measurable fuel level can be expressed as $\mathrm{h}_{0}=\mathrm{M} \tan \alpha$, or $\mathrm{h}_{0}=(\mathrm{L}-\mathrm{M}) \tan (-\alpha)$. Non-measurable fuel volume of SCT with positive and negative axial tilt can be calculated by Eq.2.3 and Eq.2.4, respectively.

$$
\begin{aligned}
& V_{0}=\frac{M\left[\sqrt{2 R h_{0}-h_{0}^{2}}\left(h_{0}-R\right)+R^{2} \cos ^{-1}\left(1-\frac{h_{0}}{R}\right)\right]}{2} \\
& V_{0}=\frac{(L-M)\left[\sqrt{2 R h_{0}-h_{0}^{2}}\left(h_{0}-R\right)+R^{2} \cos ^{-1}\left(1-\frac{h_{0}}{R}\right)\right]}{2}
\end{aligned}
$$

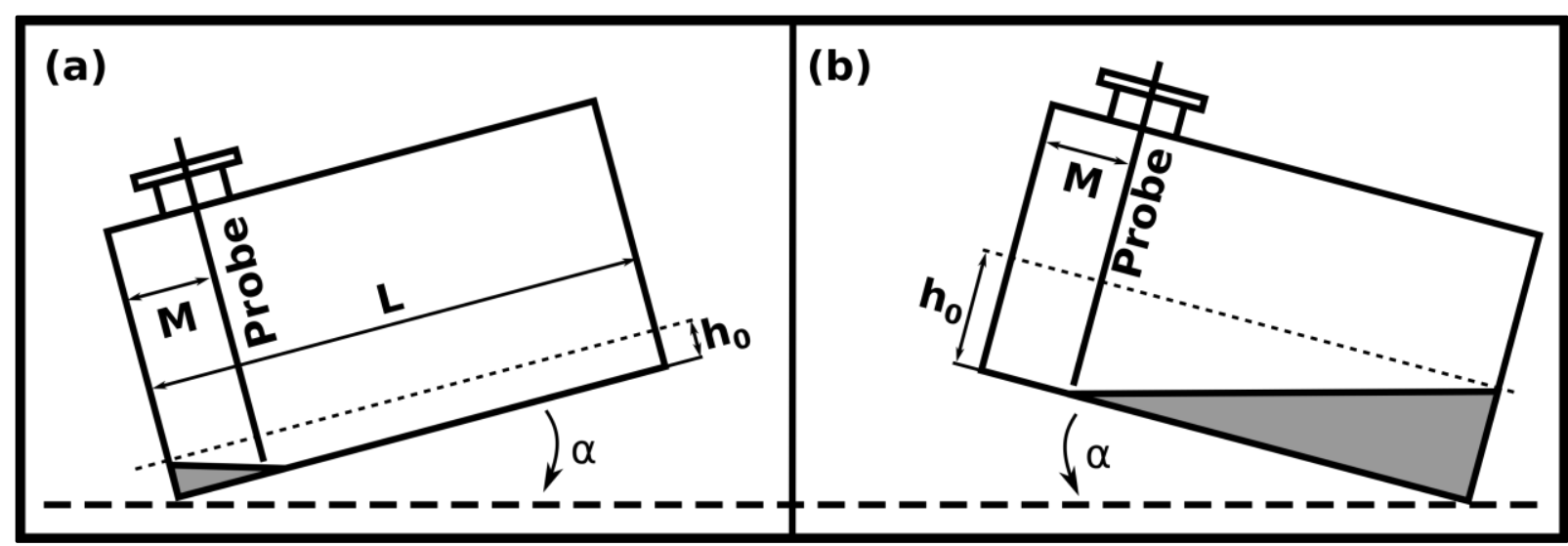

Figure 2. Nonmeasurable volume of SCT with (a) positive and (b) negative axial tilt. The parameters are, h0: Nonmeasurable fuel level in the tank, M: Probe point, L: Tank lenght, and $\alpha$ : Axial tilt angle.

At this point, to be able to express the correct liquid volume another parameter should be introduced. We define critical height $\left(h_{c}\right)$ that the increasing fuel level wets both of the tank sides (Figure 3). Depending on the tilt direction critical height can be expressed as $h_{c}=(L-M) \tan \alpha$, or $h_{c}=M \tan (-\alpha)$ similar to (Xie et al., 2012). Whether the liquid level is below or above the $h_{c}$, the total liquid volume can be expressed with different equations.

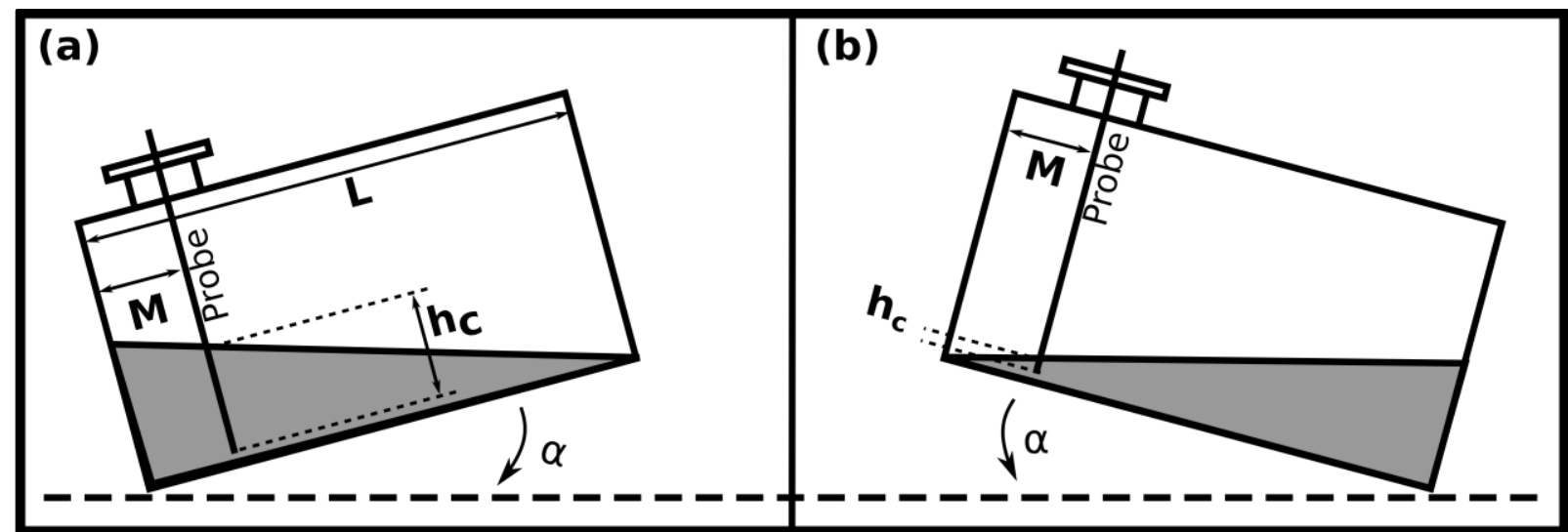

Figure 3. Critical height determination for SCT with (a) positive, and (b) negative axial tilt. The parameters are, hc: Critical height, M: Probe point, L: Tank length, $\alpha$ : Axial tilt angle 
Depending on the $h_{\alpha}$ being under or above the $h_{c}$ and the tilt angle, the liquid volume can be calculated with one of the following equations.

After obtaining theoretical SCT volume formulas, the following procedure was performed to reduce the variance. Variance can be calculated by Eq.1.2, and a volume correction term $\left(V_{\text {correction }}\right)$ is added to this formula.

For $\alpha>0$ and $h_{\alpha}>h_{c}$

$$
\mathrm{V}_{\text {total }}=\frac{\mathrm{V}\left(\mathrm{h}_{\alpha}-(\mathrm{L}-\mathrm{M}) \tan \alpha\right)+\mathrm{V}\left(\mathrm{h}_{\alpha}+\mathrm{M} \tan \alpha\right)}{2}
$$

For $\alpha<0$ and $h_{\alpha}>h_{c}$

$$
\mathrm{V}_{\text {total }}=\frac{\mathrm{V}\left(\mathrm{h}_{\alpha}+(\mathrm{L}-\mathrm{M}) \tan (-\alpha)\right)+\mathrm{V}\left(\mathrm{h}_{\alpha}-\mathrm{M} \tan (-\alpha)\right)}{2}
$$

For $\alpha>0$ and $h_{\alpha}<h_{c}$

$$
\mathrm{V}_{\text {total }}=\frac{\left(\mathrm{h}_{\alpha} \cot \alpha+\mathrm{M}\right)}{2 \mathrm{~L}} \times \mathrm{V}\left(\mathrm{h}_{\alpha}+\mathrm{M} \tan \alpha\right)
$$

For $\alpha<0$ and $h_{\alpha}<h_{c}$

$$
\mathrm{V}_{\text {total }}=\frac{\left[1-\frac{\mathrm{M} \tan (-\alpha)-\mathrm{h}_{\alpha}}{\mathrm{L} \tan (-\alpha)}\right] \times \mathrm{V}\left(\mathrm{h}_{\alpha}+(\mathrm{L}-\mathrm{M}) \tan (-\alpha)\right)}{2}
$$

The assumptions used in the calculations are i) The tank probe measures correctly the fuel heights and temperatures (i.e. probe itself is not the source of mismeasurement), ii) The sales data is exact and the pumpmat measures correctly each sales transactions, and iii) In cases of any operations, correction volume amounts are taken by site owner/operator.

There are two types of delivery (i.e. refilling of the tank) data, which are ATG delivery (measured by tank gauge) and invoiced delivery (measured by terminal gauge with respect to reference temperature, $\mathrm{T}_{\text {ref }}=15^{\circ} \mathrm{C}$ ). In order to eliminate the measurement errors, variance is calculated with respect to the invoiced delivery data in this study.

The measured liquid level is converted to volume according to the tank calibration chart under the first assumption. However, level to volume (LV) conversion may be incorrect due to inaccurate (or poor) tank calibration chart. In this case, incoming delivery (invoiced), sales and correction volume data are independent from ATG probe and tank calibration chart. In line with this information, variance formula was revised and incoming data, which was independent from ATG probe and tank calibration chart, is defined as 'actual volume change' in the below form.

$$
\text { Variance }=\Delta V_{\text {theo }}+\Delta V_{\text {actual }}=\left(V_{\text {final }}-V_{\text {initial }}\right)+\left(V_{\text {sales }}+V_{\text {correction }}-V_{\text {invoiced }}\right)
$$

The real time data includes each transaction and frequent readings of inventory level and temperature. This data was used to calculate the accurate volume by using the derived theoretical volume equations. According 
to the aforementioned assumptions, actual volume changes are accurate and were used in the variance determination. However, due to inaccurate level to volume conversion, temperature compensation was included to improve the readings as well. Temperature effect on the fuel volume is calculated using initial temperature $\left(T_{i}\right)$, final temperature $\left(T_{f}\right)$ and thermal expansion coefficient $\left(\alpha_{\text {fuel }}\right)$. In this calculation, thermal expansion coefficients of diesel and gasoline are taken as $0.000792\left(1 /{ }^{\circ} \mathrm{C}\right)$ and $0.001251\left(1 /{ }^{\circ} \mathrm{C}\right)$, respectively $(\mathrm{R} . \mathrm{W} ., 1991)$

$d V_{\text {theo }}=V_{\text {final }}-V_{\text {initial }}+\left[\alpha_{\text {fuel }} \times\left(T_{i}-T_{f}\right)\right]$

A MATLAB script was developed to process the available data using the Equations 2.1-2.10. The results are presented below.

\section{Results and Discussions}

In this section, first, we demonstrate the effects of parameters on a horizontal SCT through our models. In addition to theoretical models, real time data of a tank from a commercial fuel service station is also available. Table 1 shows the tank dimensions as reported by the manufacturer and as used in our models. At this point it should be noted that the total volume of $30000 \mathrm{~L}$ is only possible with the dish head volumes, which do not exist in most of the commercial software, as well as in our model. For this reason, to be able to reach the maximum volume of $30000 \mathrm{~L}$ we have modified the tank parameters to fit the total volume. These modified dimensions are also given in Table 1.

Table 1

Manufacturer reported and modified tank dimensions

\begin{tabular}{lll}
\hline & Manufacturer reported tank dimensions & Modified tank dimensions \\
\hline Total volume, V (L) & 30000 & 30000 \\
Radius, R (mm) & 1240 & 1250 \\
Length, L (mm) & 6000 & 6115 \\
Probe distance, M (mm) & 700 & 700 \\
Dished head depth, H (mm) & 400 & 0 \\
\hline
\end{tabular}

Initial tank calibration chart was established under ideal conditions $(\alpha=\beta=0)$. Liquid volume in the tank is calculated with the given tank sizes. Then the effects of six parameters (i.e. R, L, H, M, $\beta, \alpha$ ) on liquid volume were examined and presented below with discussions.

\subsection{Effect of Parameters on SCT Calibration Chart}

Under non-ideal conditions the actual and the measured liquid volumes show differences. From this point on, this difference will be noted as $\Delta \mathrm{V}$, which can be caused by the error in tank parameters, as well as the tilted tank position. Eq.2.1 shows the relation between the SCT volume and the length or the radius. The effects of these parameters were investigated by introducing a $\pm 10 \%$ change in relative parameters with $2 \%$ steps. Figure 4.a and Figure 4.b show $\Delta \mathrm{V}$ with respect to difference in radius and length. As expected, larger mismatches in tank radius cause larger differences in measured and actual volumes. Moreover, $\Delta \mathrm{V}$ is more pronounced in the regions in which the tank is more than half full. On the other hand, error in tank length brings a linear $\Delta \mathrm{V}$ for all the measured liquid heights. 


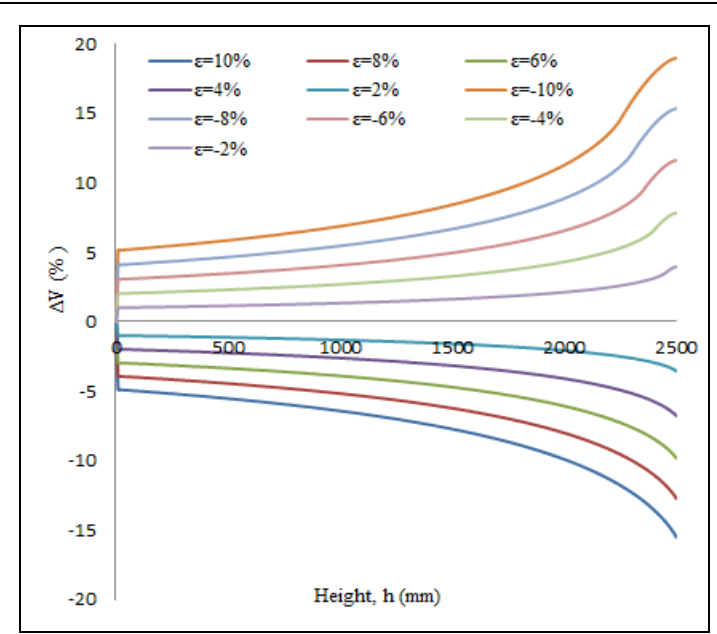

(a)

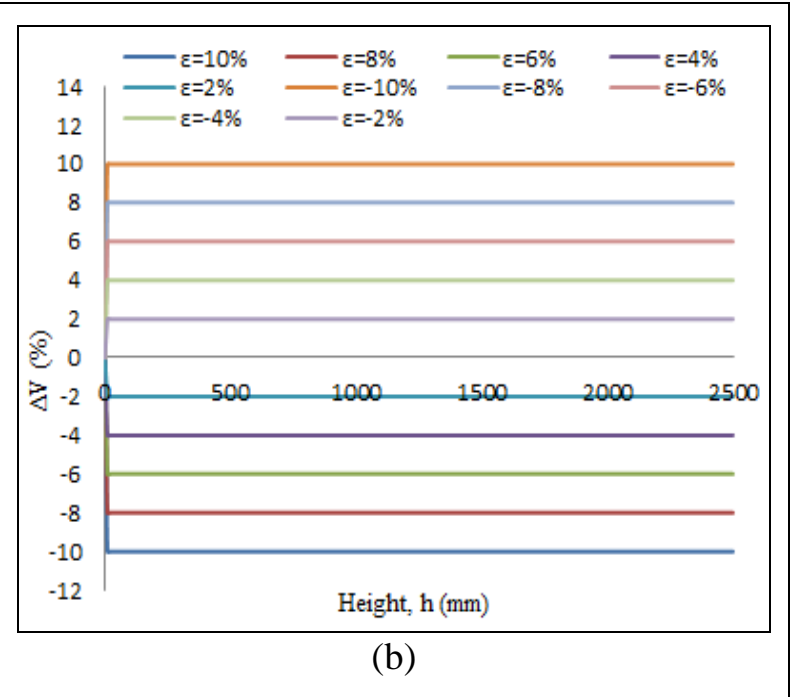

Figure 4. Percent volume change vs. height in the case of different percent error (c) in (a) radius and (b) length.

Unless the tank is tilted axially, the probe offset (M) has no effect on the measured volume. Thus, this effect was investigated in the cases of axial tilts only. Figure 5.a shows that $\Delta \mathrm{V}$ is greater for negative error in probe position at constant positive axial tilts, and vice versa. Figure 5.a shows that when $\mathrm{M}$ is decreased (i.e. $\varepsilon \%<$ 0 ), the $\Delta \mathrm{V}$ increases for constant negative axial tilts, and vice versa. In conclusion, Figure 5.a and Figure 5.b clearly show that $\Delta \mathrm{V}$ scale is much greater for the negative axial tilts. At this point it should be noted that, when the measured height approaches to zero level, the volume changes increase significantly because of the "division by zero" problem. Thus, in Figure 5.a and Figure 5.b, as well as the following figures, we limited the percent volume change at $-100 \%$. Similarly, Figure 6.a and Figure 6.b show the effects of radial tilts. In this case however, because of the symmetry, the effects of positive and negative directions are the same.

To observe the effect of the axial tilt, $\Delta \alpha$ in the range of $\pm 10^{\circ}$ with $2^{\circ}$ steps were introduced. When the tank tilt in either $\pm \alpha$ direction, the tank calibration chart is affected differently. Figure 7.a shows that, $\Delta \mathrm{V}$ is greater than one hundred percent at the lower level of SCT in the case of different positive axial tilt. We observe a sign change for the volume difference (i.e. variance) in the lower regions of the measured height for the positive axial tilts. Although in most of the cases this liquid region is too low to work, nonetheless, it may become confusing in extreme cases. Another reason of this is that, when positive axial tilts were introduced, calculated volume is much greater than originals' for the lower levels. As it is seen in the Figure 7.b, as long as the height increases, smaller $\Delta \mathrm{V}$ occurs for the introduced negative axial tilts. In sum, negative $\alpha$ brings negative $\Delta \mathrm{V}$, which means measured volume is always greater than actual volume. On the other hand, positive $\alpha$ brings positive $\Delta \mathrm{V}$ excluding the lowest tank levels (i.e. $\mathrm{h}<50 \mathrm{~mm}$ ), which means measured volume is always smaller than actual volume. 


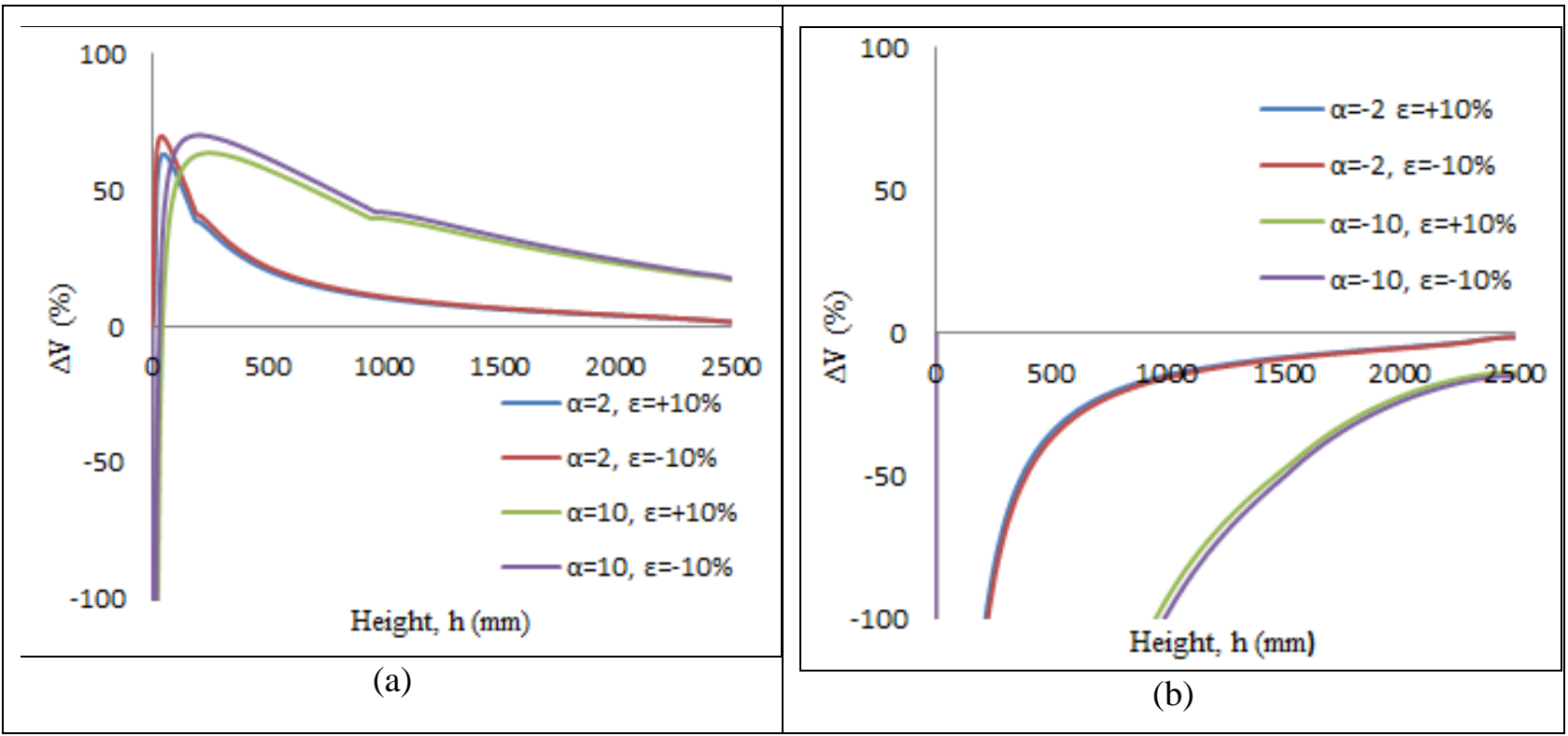

Figure 5. Percent volume change vs. height in the case of different (a) positive axial tilts and percent error $(\varepsilon)$ in probe position and (b) negative axial tilts and percent error $(\varepsilon)$ in probe position

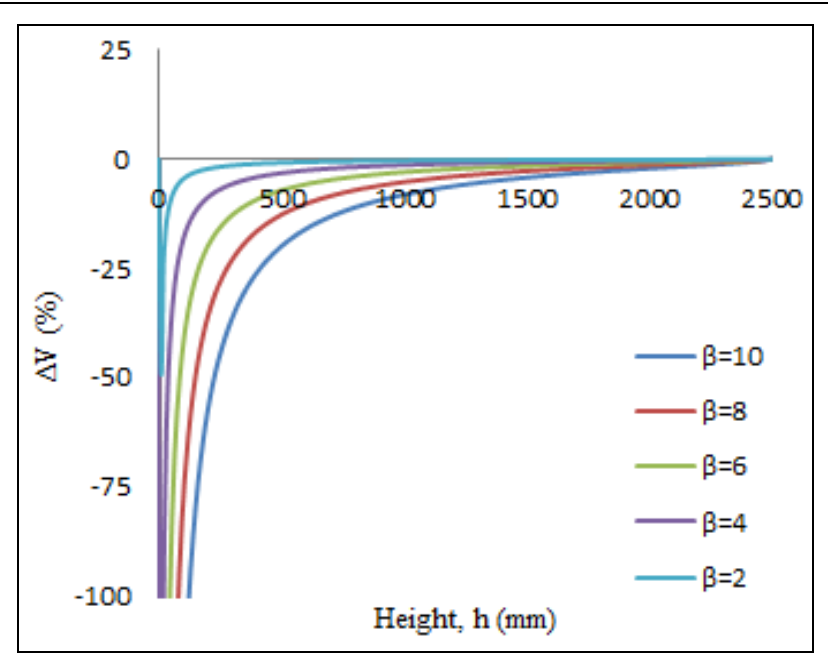

(a)

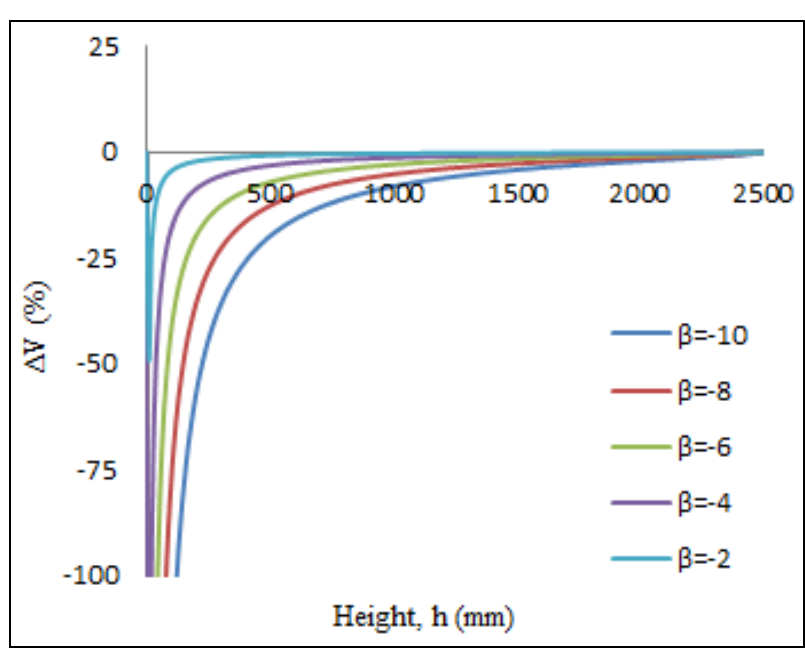

(b)

Figure 6. Percent volume change vs. height in the case of different (a) positive and (b) negative radial tilts

Next, we investigated the combination effect of two parameters on SCT volume. Firstly, the effect of axial tilt and radius were investigated by introducing positive/negative tilts and positive/negative error in radius. Figure 8. a shows that for constant positive axial tilts, $\Delta \mathrm{V}$ is greater for negative error in radius, and vice versa. Besides, $\Delta \mathrm{V}$ increases with increasing positive axial tilt. Figure 8.b shows that at constant percent error in radius, $\Delta \mathrm{V}$ increases if negative axial tilt is increased, and vice versa. In conclusion, when Figure 8.a and Figure 8.b are compared, it is obviously seen that percent volume change scale is much greater for the negative axial tilts. 


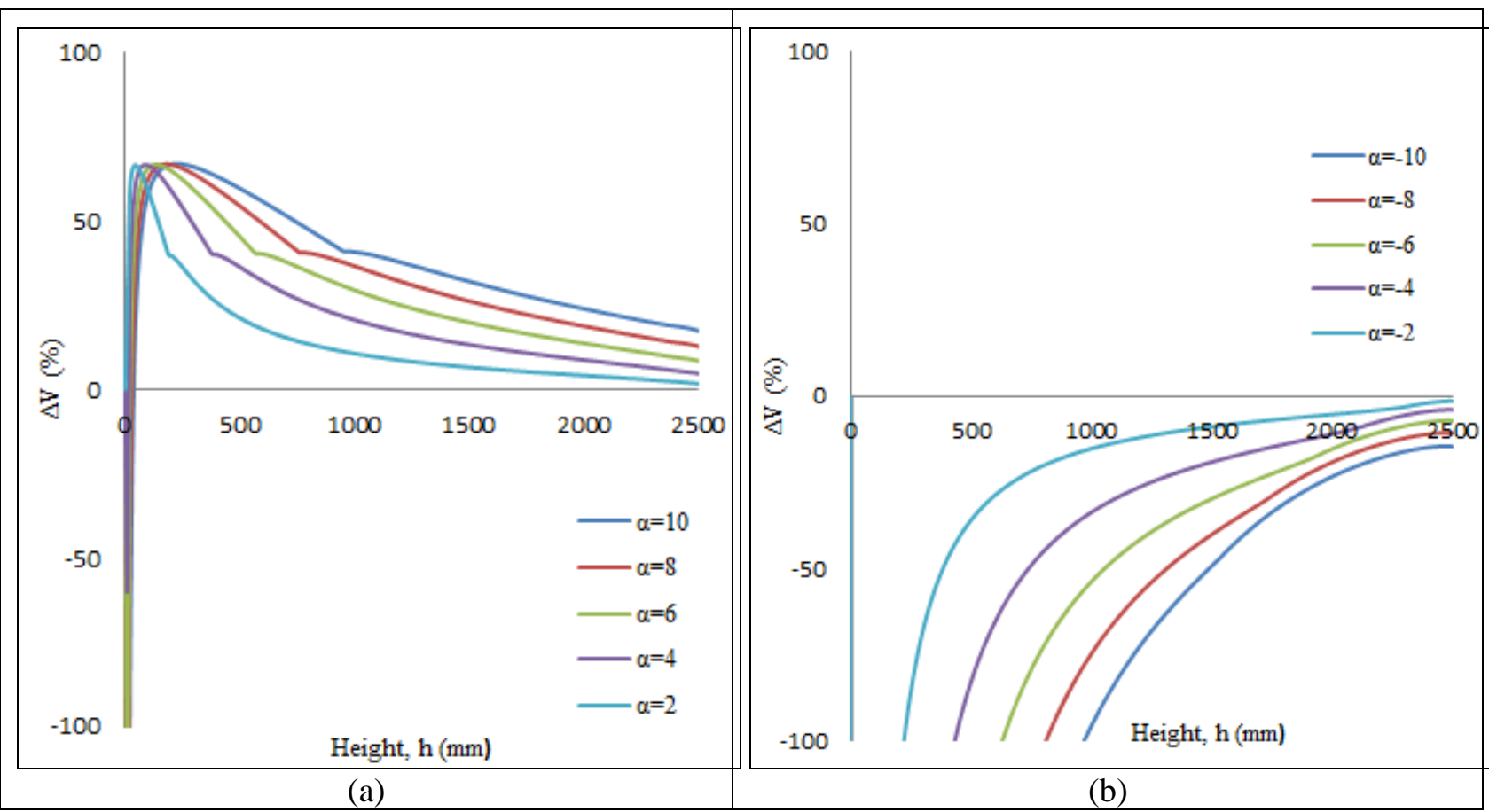

Figure 7. Percent volume change vs. height in the case of different (a) positive and (b) negative axial tilts

Figure 9 shows that radius increases (i.e. $\varepsilon \%>0$ ), $\Delta \mathrm{V}$ also increases at constant radial tilts. $\Delta \mathrm{V}$ increases with increasing error in radius and increasing radial tilt. As mentioned before, positive and negative radial tank tilts have the same effect owing to the symmetry. Therefore, while investigating of radial tilt and radius effects, only positive radial tilts were used.

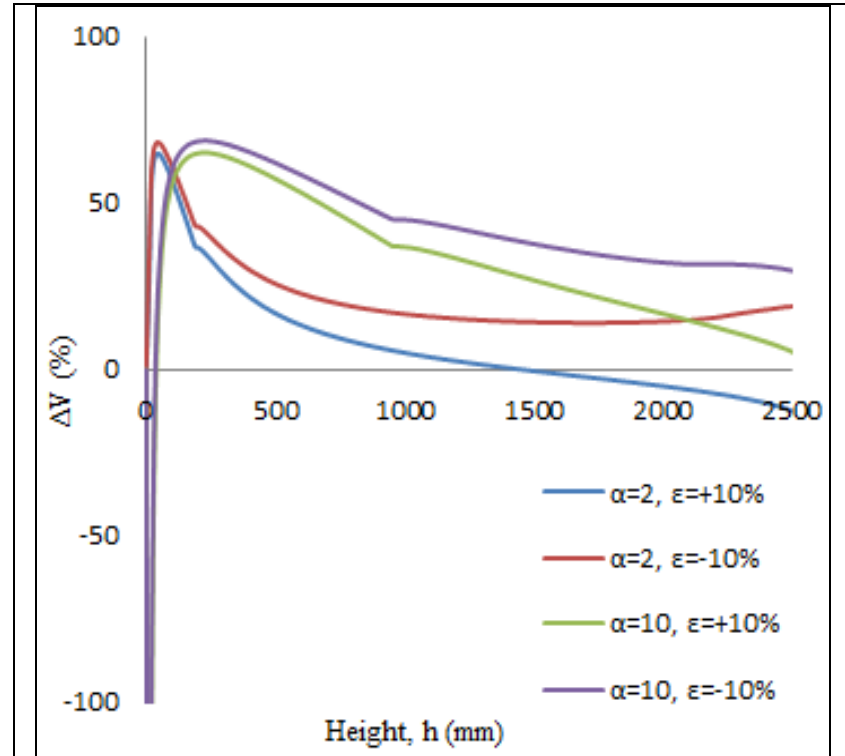

(a)

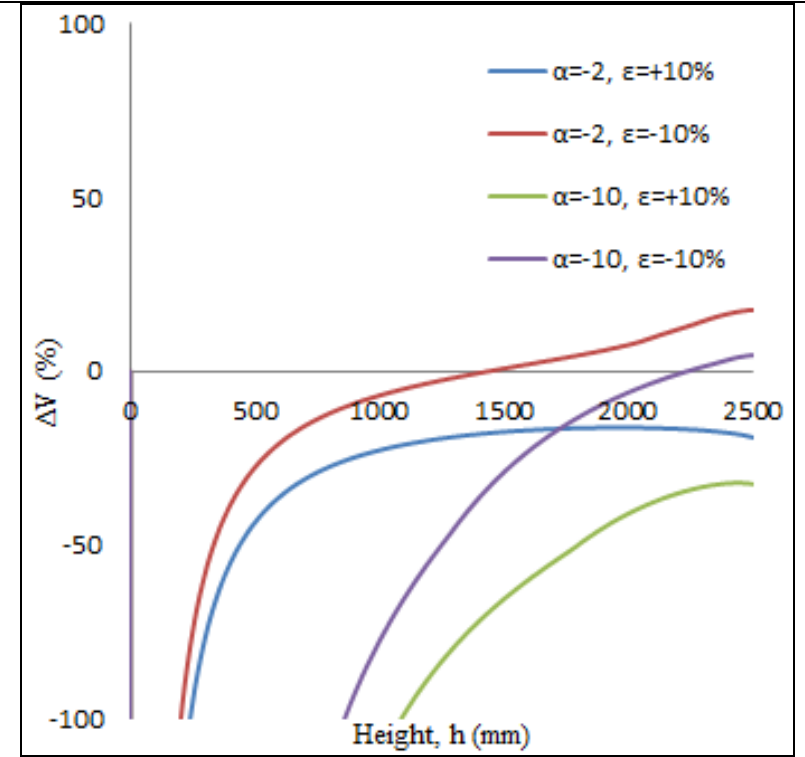

(b)

Figure 8. Percent volume change vs. height in the case of different (a) positive axial tilts and percent error $(\varepsilon)$ in radius and (b) negative axial tilts and percent error $(\varepsilon)$ in radius

Finally, we investigated the effect of temperature on diesel and gasoline volumes at the different measurement heights. During the tanker refills, invoiced delivery is obtained with respect to the fuel volume at $15^{\circ} \mathrm{C}$. Thus, all volume calculations were performed according to this reference temperature of $15^{\circ} \mathrm{C}$. Figure 10.a and Figure 10.b show $\Delta \mathrm{V}$ for diesel and $\Delta \mathrm{V}$ for gasoline are equal to zero at $15^{\circ} \mathrm{C}$, as they should be. When the height of diesel or gasoline in SCT decreases, $\Delta \mathrm{V}$ increases at constant temperature. Under the same conditions (i.e. 
temperature and all the measured liquid heights of SCT), $\Delta \mathrm{V}$ is greater for gasoline because thermal expansion coefficient $\left(\alpha_{\text {gasoline }}=0.001251\left(1 /{ }^{\circ} \mathrm{C}\right), \alpha_{\text {diesel }}=0.000792\left(1 /{ }^{\circ} \mathrm{C}\right)\right)$ of gasoline is greater.

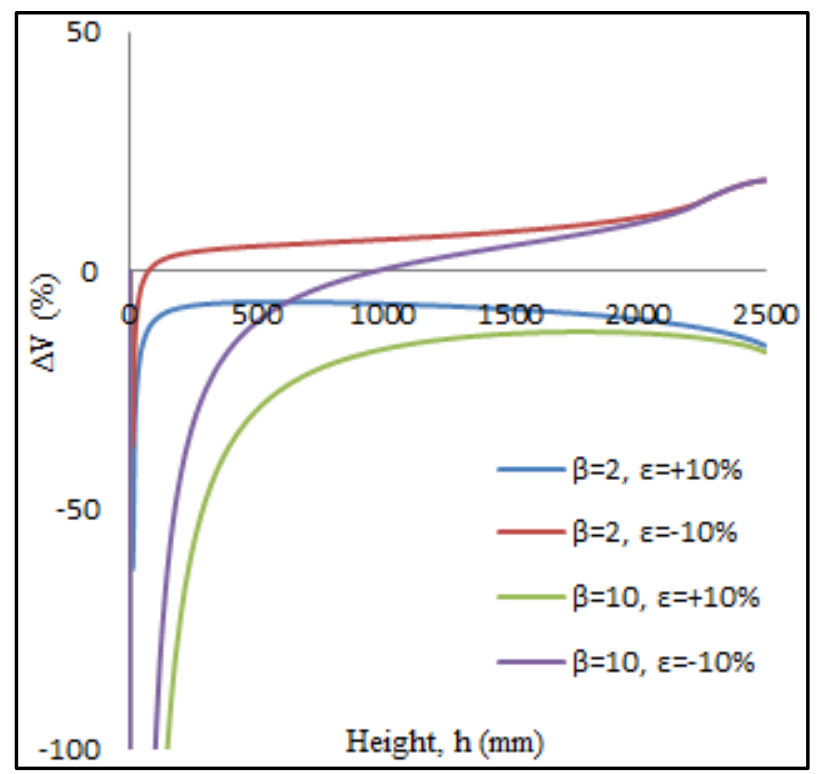

Figure 9. Percent volume change vs. height in the case of different radial tilts and percent error $(\varepsilon)$ in radius.

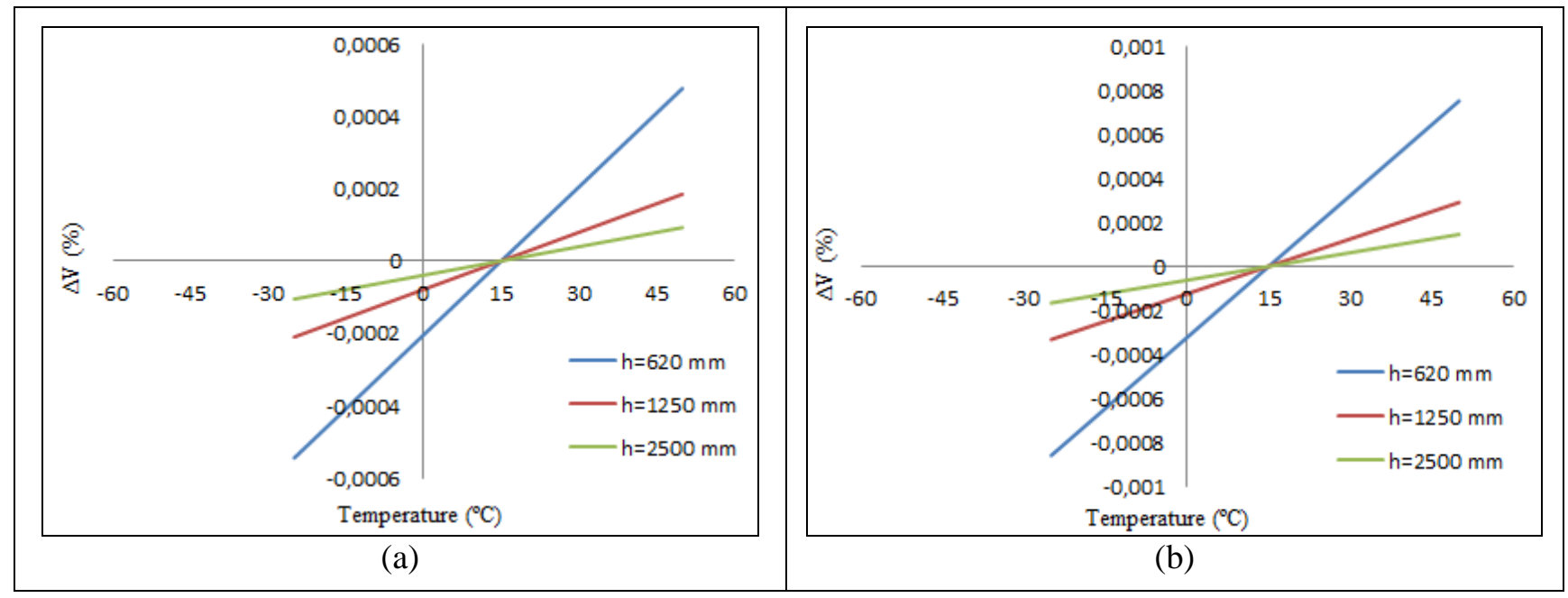

Figure 10. Percent volume change vs. temperature for (a) diesel and (b) gasoline volume at different height.

\subsection{Variance Reduction/Adjustment}

Upon observing the effect of parameters and non-idealities, we progressed to use this information to correct the errors in liquid volume $(\Delta \mathrm{V})$ by introducing (identifying) the deformation parameters. To begin with, tank calibration chart was established under ideal conditions using the data in Table 1 . Then, the variance was calculated using this calibration chart and the gathered real time data.

Figure 11 shows the variance when the ideal calibration chart is used in combination with the real time data. Under ideal conditions, the expected variance is zero for all heights, which shows that the actual and the measured liquid volumes are equal to each other. However, as Figure 11 shows, a large variance is observed for the height values between $1000 \mathrm{~mm}$ and $2500 \mathrm{~mm}$. This variance is in the range of $+100 \mathrm{~L}$ to $-300 \mathrm{~L}$. In Figure 11, different variance values can be seen for the same height value. The reason for this, as Eq.2.9 shows the variance shows a difference for the positive and negative volume changes, even if the final height is the same. 


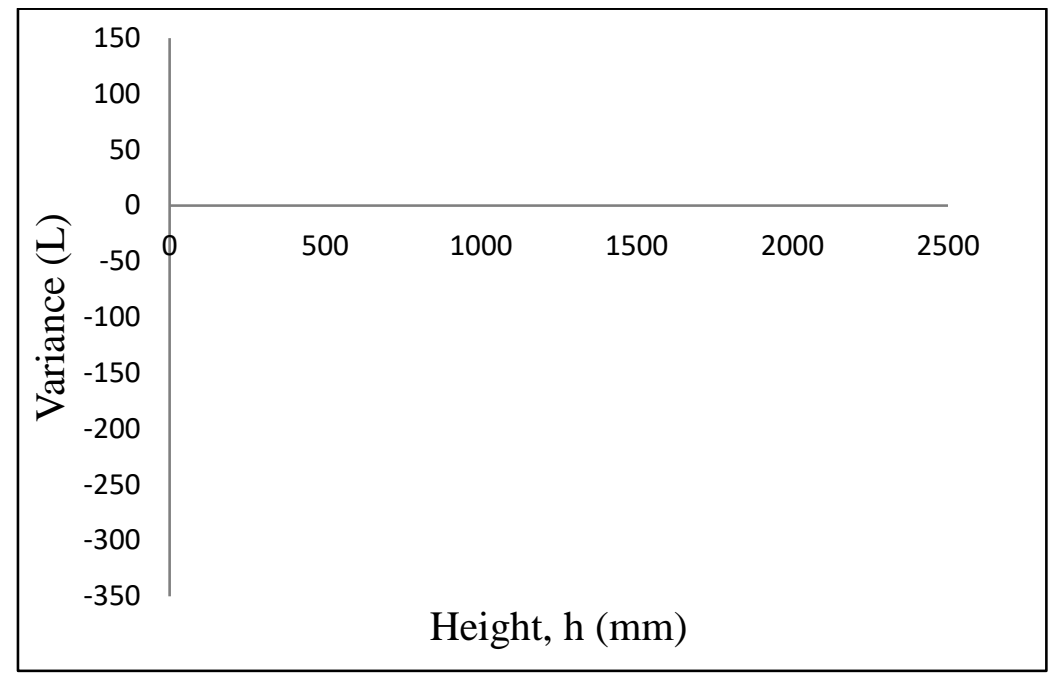

Figure 11. Current variance distribution of the selected tank.

In order to correct the volume differences and estimate the correct volume of the liquid, the real time data was split into two groups. The first group was used to determine deviations in the tank parameters and the second group was used to test the new parameters for the variance. Using simple trial and error procedure corrections of the tank parameters were obtained, such that the variance is minimized for the first group of data.

Table 2 compares the theoretical and corrected tank parameters. Our models predicted an axial tilt of $\alpha=-0.10^{\circ}$, and radial tilt of $\beta=0.10^{\circ}$, which are highly probable for an underground tank. Although the changes in the parameters (i.e. $\alpha$ and $\beta$ ) are relatively small, owing to the large tank dimensions and total volume, the deviations of the calculated liquid (fuel) volume make a large difference.

Table 2

Comparison of theoretical and corrected tank dimensions

\begin{tabular}{llll}
\hline Parameters & Theoretical tank dimensions & Corrected tank dimensions & Change (\%) \\
\hline $\mathrm{R}, \mathrm{mm}$ & 1250 & 1270 & $20 \mathrm{~mm}(1.60 \%)$ \\
$\mathrm{L}, \mathrm{mm}$ & 6115 & 6200 & $85 \mathrm{~mm}(1.39 \%)$ \\
$\mathrm{M}, \mathrm{mm}$ & 700 & 700 & No change \\
$\mathrm{H}, \mathrm{mm}$ & 0 & 0 & No change \\
Alpha, Degree & 0 & -0.10 & $-0.10^{\circ}$ \\
Beta, Degree & 0 & 0.10 & $0.10^{\circ}$ \\
Capacity, L & 30000 & 31332 & $1332 \mathrm{~L}(4.44 \%)$
\end{tabular}

These corrected tank parameters were then used to obtain a corrected calibration chart. In addition, effect of temperature was also included into the new volume calculations. Using all the corrections second group of data was tested for the variance. Figure 12 shows the effect of the new parameters (i.e. corrections) on the variance, presented for all the data. It can clearly be seen that the model (i.e. corrected) variance approaches to an ideal case of zero. Thus, the inaccurate level to volume conversion was improved by variance minimization and a new accurate tank calibration chart was established. In addition, the masking effect of poor calibration chart was eliminated and the accuracy of level to volume conversion was increased.

In Figure 12, the sum of the absolute values of the actual variance is $7164 \mathrm{~L}$. That of corrected model is 2347 $\mathrm{L}$. The daily average of the corrected value for 126 days is $18.7 \mathrm{~L} /$ day which is well below the $288 \mathrm{~L} /$ day limit (EPDK, 2019). Furthermore, the hourly average of the corrected data is $0.77 \mathrm{~L} / \mathrm{h}$. Assuming the variance is caused by a leak, unfortunately this value exceeds the threshold value of $\sim 0.4 \mathrm{~L} / \mathrm{h}$ (NWGLDE, 2020). 
Nonetheless, these results show that our approach brings a $67.2 \%$ improvement with respect to the ideal (i.e. zero variance) case.

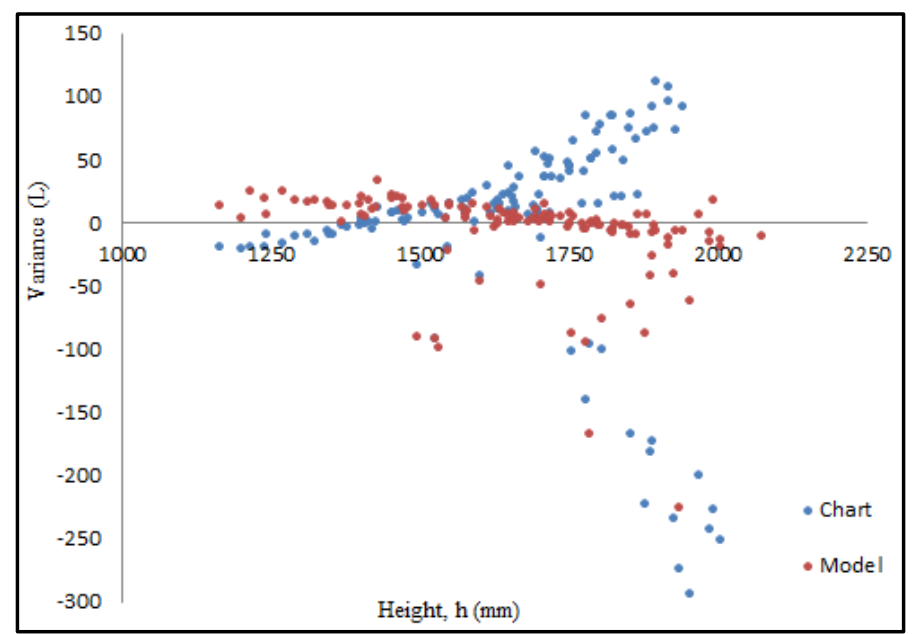

Figure 12. Variance comparison of current chart and model with all data groups for the selected tank

The similar previous studies either focus on correcting the calibration charts or wet-stock management and/or leak detection. Although the aims and the scopes of these studies are different from current study a few comparisons can be made. First, when the calibration correction is investigated our results are in line with the previous works where mathematical models are used (Chen, 2012; Khaisongkram \& Banjerdpongchai, 2004; Y. Li, 2014; Nosach, 2000; Sigut, Alayón, \& Hernández, 2014). Second, from the wet-stock management and leak detection point of view, the reduced variance (67.2\%) appears to be a good improvement compared to similar works (Caihong Li, 2013; Gorawski et al., 2017; Z. Li, Shui, Luo, Chen, \& Li, 2011; Sigut et al., 2014). At this point we would like to speculate on the resulting volume difference above the threshold value. It is possible that this result stems from the highly deformed tank from which the data is obtained. Whereas the previous studies worked with a volume difference of a few liters (Gorawski et al., 2017; Z. Li et al., 2011) that of current data is within the range of $+100 \mathrm{~L}$ to $-300 \mathrm{~L}$. Thus, we believe that in the case of a tank with a lower variance range, the method would produce acceptable results well below the threshold of $0.4 \mathrm{~L} / \mathrm{h}$.

\section{Conclusions}

This study aims to provide a way of variance minimization for underground storage tanks (USTs) to improve the wet stock management and leak detection. For this purpose, mathematical models that parameterize the deformations in the tank parameters were derived. The considered parameters were tank measurements (R, L, M), tank tilts in axial and radial axes as well as liquid temperature. To begin with sufficient information on the tank dimensions should be available along with the height to volume data, which is readily available. Using the models derived in this study, the variance that stems from inaccurate (poor) calibration charts or physical deformations (i.e. buckling) can be reduced significantly without the necessity of re-calibration using physical methods. Testing the developed method on an actual data reduced the variance by $67.2 \%$, which shows the validity of the developed method.

\section{Acknowledgement}

This work did not receive any funding.

\section{Author Contributions}

Ayşe Nur Dalman: Graduated M.Sc. student. Collected data and performed the analysis. Performed statistical analysis and wrote the paper. 
M. Oluş Özbek: Thesis supervisor. Conceived and designed the analysis. Performed statistical analysis and wrote the paper.

\section{Conflicts of Interest}

The authors declare that the current work is derived from the M.Sc. thesis of Ayşe Nur Dalman, which was supervised by M. Oluş Özbek and completed in 13 December 2017, under Chemical Engineering Department, Graduate School of Natural And Applied Sciences, Yeditepe University.

\section{References}

Accessories For Chromatography (AFC). (2010). Combustibles. Retrieved from Gas Detection \& Air Monitoring Specialists: http://www.afcintl.com/pdfs/applications/combustibles.pdf

Advanced Practice Education Associates (APEA). (2009). APEA Training Course - Wetstock Management. Retrieved from England: https://apea.org.uk/pages/training

Asis Otomasyon Akaryakit Sistemleri (ASIS). (2017). CalibeX 3D Laser Calibration. Retrieved from https://www.youtube.com/watch?v=eIg7wENiQJA

Caihong Li, Y. Y., Lulu Song, Yunjian Tan, and Guochen Wang. (2013). Mathematical Model Based on BP Neural Network Algorithm for the Deflection Identification of Storage Tank and Calibration of Tank Capacity Chart. 13. https://doi.org/10.1155/2013/923036

Chen, Z. Y. S. (2012). Deformation Identification and Tank Capacity Table Calibration of the Storage Tank $\begin{array}{llll}\text { Applied Mechanics and } & \text { Materials, 110-113. }\end{array}$ https://doi.org/10.4028/www.scientific.net/AMM.184-185.110

Environmental Protection Agency (EPA). (2013). Wetstock Reconciliation at Fuel Storage Facilities - An Operator's Guide. Retrieved from: http://oldsite.apea.org.uk/download/Wetstock Reconciliation_At_Fuel_Storage_Facilities.pdf

European Committee for Standardization (EN). (2016). Leak detection systems - Part 5: Requirements and test/assessment methods for in-tank gauge systems and pressurised pipework systems. Retrieved from https://standards.iteh.ai/catalog/standards/cen/eb73f5f1-eb15-44a2-91b7-603a1a33c464/en-13160-52016

Environmental Protection Agency (EPA). (1995). Introduction to Statistical Inventory Reconciliation for Underground Storage Tanks. Retrieved from US: https://www.epa.gov/ust/introduction-statisticalinventory-reconciliation-underground-storage-tanks

Environmental Protection Agency (EPA). (2005). Straight Talk on Tanks, Leak Detection Methods for Petroleum Underground Storage Tanks and Piping. Retrieved from US: https://nepis.epa.gov

Environmental Protection Agency (EPA). (2015). Musts for USTs. Retrieved from Washington: https://www.epa.gov/ust/musts-usts

Environmental Protection Agency (EPA). (2017). Learn About Underground Storage Tanks (USTs). In: EPA. https://www.epa.gov/ust

Environmental Protection Agency (EPA). (2017). Release Detection and Inventory Control for Petroleum Storage Tanks. Retrieved from: https://www.epa.gov/ust/release-detection-underground-storagetanks-usts

Enerji Piyasası Denetleme Kurumu (EPDK). (2019). 1240 Sayılı Kurul Kararında Değişiklik Yapılmasına Dair Kurul Kararl. Retrieved Ankara: https://www.resmigazete.gov.tr/eskiler/2019/05/20190521.pdf

ERC. (2016). Design, Commissioning, Decommissioning and Recommissioning of Petroleum Retail Service Stations Retrieved from https://publishing.energyinst.org/topics/petroleum-product-storage-anddistribution/filling-stations

Gorawski, M., Gorawska, A., \& Pasterak, K. (2017). The TUBE algorithm: Discovering trends in time series for the early detection of fuel leaks from underground storage tanks. Expert Systems with Applications, 90, 356-373.https://doi.org/10.1016/j.eswa.2017.08.016

Jin Tao Wang, Z. Y. L., Lin Tong, Li Gong Guo, Xue Song Bao, Long Zhang. (2013). Precise Measurement on Form of Horizontal Tank Used for Liquid Volume Metrology by Laser Method. Applied Mechanics and Materials, (239-240). Trans Tech, Switzerland. https://doi.org/10.4028/www.scientific.net/AMM.239-240.152 
Keating, J. P., \& Mason, R. (2000). Using statistical models to detect leaks in underground storage tanks (Vol. 11). https://doi.org/10.1002/1099-095X(200007/08)11:4\%3C395::AID-ENV420\%3E3.0.CO;2-K

Khaisongkram, W., \& Banjerdpongchai, D. (2004). A combined geometric-volumetric calibration of inclined cylindrical underground storage tanks using the regularized least-squares method (Vol. 2). https://doi.org/10.1109/CCA.2004.1387590

Knyva, V., \& Knyva, M. (2012). New Method for Calibration of Horizontal Fuel Tanks. 2012, 18(9). Retrieved from http://eejournal.ktu.lt/index.php/elt/article/view/2816

Li, Y. (2014). Research on Horizontal Tank Position Identification and Capacity Indicator Calibration. Applied Mechanics and Materials, 443, 662-667. doi:10.4028/www.scientific.net/AMM.443.662

Li, Z., Shui, A., Luo, K., Chen, J., \& Li, M. (2011, 23-25 May 2011). SIR-based oil tanks leak detection method. Paper presented at the 2011 Chinese Control and Decision Conference (CCDC). https://doi.org/10.1109/CCDC.2011.5968519

Mensura. (2013). Mensura 3D Laser Scan Retrieved from http://mensura.com.tr/3D.html

Nosach, V. V. (2000). Calculation of the Calibration Characteristics of Inclined Cylindrical Storage Tanks by a Geometric Method. Measurement Techniques, 43(10), 871-876. https://doi.org/10.1023/A:1007603409659

National Work Group On Leak Detection Evaluations (NWGLDE). (2020). Statistical Inventory Reconciliation Test Method. Retrieved from http://www.nwglde.org/methods/sir_quantitative.html

R. W., M. J. W. H. (1991). Chemical Stored in USTs: Characteristics and Leak Detection. https://nepis.epa.gov/Exe/ZyNET.exe/30000HOC.TXT

Shinn, R. C. (2001). A Guide to the Operation and Maintenance of Your Underground Storage Tank System Retrieved from New Jersey: https://www.epa.gov/sites/production/files/201602/documents/om_final_2-17-16_508_0.pdf

Sigut, M., Alayón, S., \& Hernández, E. (2014). Applying pattern classification techniques to the early detection of fuel leaks in petrol stations. Journal of Cleaner Production, 80, 262-270. https://doi.org/10.1016/j.jclepro.2014.05.070

Tora Petrol Ürünleri Mühendisliği Elektrik ve Elektronik Sanayi ve Ticaret A.Ş. (TORA). (2016). TORA Training- Fuel Service Stations Technical Safety Retrieved from https://torapetrol.com/

Türk Standartları Enstitüsü (TSE). (2006). TS 12820 Petrol Filling Stations - Safety Requirements. Retrieved from https://www.resmigazete.gov.tr/eskiler/2007/05/20070520-12.htm

Veeder-Root Co. (VR). (2009). TLS Magnetostrictive Technology. In Veeder-Root (Ed.). https://www.veeder.com/us/automatic-tank-gauging-products/leak-detection-and-monitoringsensors/sump-monitoring-sensors/magnetostrictive-discriminating-dispenser-pan-containment-sumpsensor

Veeder-Root Co. (VR). (2013). TLS Foundation Training for TLS Gauge Engineers. Environmental Systems. Veeder-Root. https://www.veeder.com/us/technical-support/tls-350-operator-tips

Veeder-Root Co. (VR). (2015). Fuel Management Services (FMS) - SIR Environmental. Retrieved from https://www.gilbarco.com/la/en/products/services/fms

Veeder-Root Co. (VR). (2016). Detecting and Reducing Loss in Your Fueling System. Retrieved from https://www.veeder.com/us/detecting-and-reducing-loss-your-fueling-system

Xie, W., Wang, X., Cui, H., \& Chen, J. (2012). Optimization Model of Oil-Volume Marking with Tilted Oil Tank. Open Journal of Optimization, 1(2), 5. http://dx.doi.org/10.4236/ojop.2012.12004

West Yorkshire Fire And Recue Service (Yorkshire), W. (2014). Petrol Stations - Wetstock Control. Retrieved from West Yorkshire: https://www.westyorksfire.gov.uk/safety-leaflet/petrol-stations-wet-stockcontrol/petrol-stations-wet-stock-control-2/

Work Safe Queensland. (2016). A Guide for Service Station Operators under the Work Health and Safety Act Retrieved from https://www.worksafe.qld.gov.au/_data/assets/pdf_file/0018/18315/guide-servicestation-op.pdf 